\title{
Is red blood cell distribution width an indicator of prognosis and mortality in respiratory intensive care unit?
}

\author{
Güler Eraslan Doğanay॰, Mustafa Özgür Cırık॰
}

Department of Anesthesiology and Reanimation, University of Health Sciences, Atatürk Chest Diseases and Thoracic Surgery Training and Research Hospital, Ankara, Turkey

\section{ABSTRACT}

Objectives: The range of variation of erythrocytes measured as Red blood cell distribution width (RDW). Mortality indicators in patients in intensive care depend on variation of physiological variables. High RDW rates have been commonly associated with heart disease, pulmonary embolism and pulmonary hypertension, peripheral artery disease, heart failure, liver disease and infectious diseases. We aimed in this study to determine the effect of RDW on prognosis and mortality in Chronic Obstructive Pulmonary Disease (COPD) patients in intensive care unit (ICU).

Methods: The cases who are treated for COPD in ICU between January 1, 2018 and December 31, 2019 reviewed. Demographic data, Charlson Comorbidite Index (CCI), Acute Physiology and Chronic Health Evaluation II (APACHE II), Sequential Organ Failure Assessment (SOFA) scores, procalcitonin, white blood cell, RDW, C-reactive protein, duration of mechanical ventilation, inotrope requirement, length of stay ICU, and 30-day mortality reviewed.

Results: Total number of 369 cases are included into the study and divided in two groups according to their RDW values (High RDW and normal RDW group). High RDW group had longer length of stay in ICU and hospital, mechanical ventilation duration, higher APACHE II, CCI, SOFA, white blood cell and procalcitonin values and lower C-reactive protein compared to normal RDW group. First outcome was hospital 30-day mortality in ICU. The age, RDW, inotrope use, MV duration, LOS H, APACHE II, CCI, SOFA, procalcitonin, CRP, HGB and HCT levels were found to be higher in patients with mortality compared those without. With the sensitivity value of $70.9 \%$ and the specificity of $47.7 \%$, RDW the cut off value was found to be 16.5 .

Conclusions: The risk of 30-day mortality, length of stay ICU and hospital and mechanical ventilation duration was higher in COPD patients with high RDW levels.

Keywords: RDW, ICU, COPD, mortality, indicator

T he range in the volume and size of the red blood cells are measured with the test named red cell distribution width (RDW) [1]. RDW is always included in the complete blood count panel and inexpensive to do. The normal range is $11.6-17.2 \%$. Although RDW is traditionally used to differentiate the type of anema, in recent studies, high RDW rates are found to be associated with heart disease, heart failure, acute pulmonary embolism and pulmonary hypertension, peripheral artery disease, liver disease, and infectious diseases [2-7]. Additionally, the RDW values have also been shown to be high in other critically 
ill patients with pneumonia, Gr (-) bacteriemia, and sepsis in intensive care unit (ICU) and it was a risk factor for hospital mortality [8-11].

Metabolic abnormalities like oxidative stress and inflamation in the cells are linked to high RDW levels and might be the main cause of the mortality in critically ill patients [12]. Mortality indicators in patients admitted to ICU depend on many physiological variables.

This research is aimed to determine the prognostic value of RDW and its relationship with mortality in patients with Chronic Obstructive Pulmonary Disease (COPD) in intensive care.

\section{METHODS}

The retrospective study was initiated after approval from the Medical Specialization Training Board of Ataturk Chest Diseases and Thoracic Surgery Training and Research Hospital (approval date \& number: $12 / 17 / 2020 \& 705)$.

The cases who were admitted to ICU between January 1, 2018 and December 31, 2019 were reviewed retrospectively. The study included patients aged 18 years and older, admitted to ICU with a diagnosis of COPD between January 1, 2018 and December 31, 2019.

Exclusion criteria were as follows; cases with

Table 1. Demographics and prognostic factors of the patients according to RDW distribution

\begin{tabular}{|c|c|c|c|c|c|c|}
\hline \multicolumn{2}{|c|}{$n=369$} & \multicolumn{4}{|c|}{ RDW (\%) } & \multirow[t]{3}{*}{$p$ value } \\
\hline & & \multicolumn{2}{|c|}{$\begin{array}{l}\text { Normal RDW } \\
\quad(n=216)\end{array}$} & \multicolumn{2}{|c|}{$\begin{array}{c}\text { High RDW } \\
(n=153)\end{array}$} & \\
\hline & & $\bar{X} \pm \mathbf{S D}$ & $\begin{array}{l}\text { Median } \\
\text { (IQR) }\end{array}$ & $\overline{\boldsymbol{X}} \pm \mathbf{S D}$ & $\begin{array}{l}\text { Median } \\
\text { (IQR) }\end{array}$ & \\
\hline \multirow[t]{2}{*}{ Gender } & Female & \multicolumn{2}{|c|}{$84(38.9 \%)$} & \multicolumn{2}{|c|}{$55(35.9 \%)$} & 0.566 \\
\hline & Male & \multicolumn{2}{|c|}{$132(61.1 \%)$} & \multicolumn{2}{|c|}{$98(64.1 \%)$} & \\
\hline \multicolumn{2}{|c|}{ Age (year) } & \multicolumn{2}{|c|}{$72.76 \pm 11.45$} & \multicolumn{2}{|c|}{$71.14 \pm 11.17$} & 0.178 \\
\hline \multicolumn{2}{|c|}{30 day mortality } & \multicolumn{2}{|c|}{$68(31.5 \%)$} & \multicolumn{2}{|c|}{$66(43.1 \%)$} & 0.022 \\
\hline \multicolumn{2}{|c|}{ Inotrope use } & \multicolumn{2}{|c|}{$51(23.6 \%)$} & \multicolumn{2}{|c|}{$37(24.2 \%)$} & 0.899 \\
\hline \multicolumn{2}{|c|}{ LOS H (day) } & \multicolumn{2}{|c|}{$15(15)$} & \multicolumn{2}{|c|}{$19(16)$} & 0.009 \\
\hline \multicolumn{2}{|c|}{ LOS ICU (day) } & \multicolumn{2}{|c|}{$3(4)$} & \multicolumn{2}{|c|}{$4(7)$} & 0.016 \\
\hline \multicolumn{2}{|c|}{ MV duration (day) } & \multicolumn{2}{|c|}{$0(2)$} & \multicolumn{2}{|c|}{$0(4)$} & 0.026 \\
\hline \multicolumn{2}{|c|}{ APACHE II } & \multicolumn{2}{|c|}{$20(7)$} & \multicolumn{2}{|c|}{$20(11)$} & 0.046 \\
\hline \multicolumn{2}{|l|}{$\mathrm{CCI}$} & \multicolumn{2}{|c|}{$6(3)$} & \multicolumn{2}{|c|}{$6(3)$} & 0.027 \\
\hline \multicolumn{2}{|l|}{ SOFA } & \multicolumn{2}{|c|}{$5(2)$} & & & 0.021 \\
\hline $\operatorname{WBC}(\times$ & (ml) & & & & 7.6) & 0.050 \\
\hline Procalci & $\mathrm{n}(\mathrm{ng} / \mathrm{ml})$ & 0.1 & 64) & 0.2 & $2.8)$ & $\mathbf{0 . 0 3 7}$ \\
\hline $\mathrm{CRP}(\mathrm{m}$ & & 33.8 & .12) & 7.7 & $.83)$ & 0.015 \\
\hline $\mathrm{HGB}(\mathrm{g}$ & & 12. & 35) & & & 0.055 \\
\hline HCT $(\%$ & & & & 37. & $3.2)$ & 0.471 \\
\hline
\end{tabular}

Continuous variables are expressed as either the mean \pm standard deviation (SD) or the median (IQR ), and categorical variables are expressed as either ${ }^{\delta}$ frequency or percentage. Continuous variables were compared with a student $\mathrm{t}$ test or the mann whitney u test, and categorical variables were compared using Pearson's chi-square test or fisher exact test. RDW $=$ Red blood cell distribution width, LOS H = Length of stay Hospital, LOS ICU = Length of stay Intensive Care Unit, MV = Mechanical Ventilation, APACHE II = Acute Physiology and Chronic Health Evaluation II, CCI = Charlson Comorbidite Index, SOFA = Sequential Organ Failure Assessment, WBC = White blood cell, CRP $=$ C-reactive protein, $\mathrm{HGB}=$ Hemoglobin, $\mathrm{HCT}=$ Hematocrit 
known hematological malignancy, recent blood transfusion and anemia (hemoglobin $<13.5 \mathrm{~g} / \mathrm{dl}$ in males, hemoglobin $<12.0 \mathrm{~g} / \mathrm{dl}$ in females are accepted as anemia), cases who were stayed in ICU less than one day and cases who had a pathology or medical condition makes RDW lower than 11.6.

The normal range of RDW is 11.6-17.2, the cases with $\mathrm{RDW} \geq 17.3$ are included into the high RDW group.

Clinical data like demographics, Charlson Comorbidite Index (CCI), Acute Physiology and Chronic Health Evaluation II (APACHE II) and Sequential Organ Failure Assessment (SOFA) scores, procalcitonin, white blood cell (WBC), C-reactive protein (CRP) values, length of stay ICU (LOS ICU), length of stay hospital (LOS H), mechanical ventilation (MV) duration, inotrope use, hemoglobin (HGB), hematocrit (HCT) and RDW values are noted. The mortality data has been taken from the Death Notification System.

\section{Statistical Analysis}

The results were compared using Statistical Package for the Social Sciences, version 22.0 (SPSS Inc., Chicago, IL, United States). Whether the distribution of continuous variables was normal or not was determined by Kolmogorov Smirnov test. Continuous data were described as mean $\pm \mathrm{SD}$ and median (interquartile range) for skewed distributions. Categorical data presented as numbers and percentages. Categorical variables were compared using Pearson's chi-square test or fisher's exact test. Firstly, possible risk factors that thought to be related with mortality were analyzed in one variable multinominal logistic regression analyzed. Variables with $p<0.25$ in univariate logistic regression analysis were included in multivariate logistic regression analysis. The Backward Wald method was used for multivariate logistic regression analysis. ROC curve analysis was used to determine the cut off points. The $p$-value $<0.05$ is accepted as significant

Table 2. The factors affecting mortality in COPD patients

\begin{tabular}{|c|c|c|c|c|c|c|c|c|c|c|}
\hline \multirow[t]{3}{*}{$n=369$} & \multicolumn{5}{|c|}{ Univariate Analysis } & \multicolumn{5}{|c|}{$\begin{array}{l}\text { Multivariate Analysis } \\
\text { (Backward wald } 6^{\text {th }} \text { step) }\end{array}$} \\
\hline & \multirow[t]{2}{*}{ Wald } & \multirow[t]{2}{*}{$p$ value } & \multirow[t]{2}{*}{ OR } & \multicolumn{2}{|c|}{$\begin{array}{l}95 \% \text { CI for } \\
\text { EXP(B) }\end{array}$} & \multirow[t]{2}{*}{ Wald } & \multirow[t]{2}{*}{$p$ value } & \multirow[t]{2}{*}{ OR } & \multicolumn{2}{|c|}{$\begin{array}{l}\text { 95\% CI for } \\
\text { EXP(B) }\end{array}$} \\
\hline & & & & Lower & Upper & & & & Lower & Upper \\
\hline Age (year) & 7.332 & 0.007 & 1.027 & 1.007 & 1.047 & & & & & \\
\hline Gender & 0.306 & 0.580 & 1.132 & 0.729 & 1.758 & & & & & \\
\hline RDW (\%) & 5.822 & 0.016 & 1.076 & 1.014 & 1.141 & & & & & \\
\hline LOS H (day) & 2.042 & 0.153 & 0.989 & 0.975 & 1.004 & 10.049 & 0.002 & 0.966 & 0.946 & 0.987 \\
\hline LOS ICU (day) & 9.141 & 0.002 & 1.056 & 1.019 & 1.095 & & & & & \\
\hline $\begin{array}{l}\text { MV duration } \\
\text { (day) }\end{array}$ & 20.847 & $<0.001$ & 1.111 & 1.062 & 1.163 & 11.650 & 0.001 & 1.081 & 1.034 & 1.130 \\
\hline APACHE II & 45.444 & $<0.001$ & 1.130 & 1.090 & 1.170 & 10.350 & 0.001 & 1.073 & 1.028 & 1.121 \\
\hline $\mathrm{CCI}$ & 19.046 & $<0.001$ & 1.295 & 1.153 & 1.455 & & & & & \\
\hline SOFA & 67.431 & $<0.001$ & 1.751 & 1.532 & 2.001 & 30.189 & $<0.001$ & 1.519 & 1.309 & 1.763 \\
\hline $\mathrm{WBC}\left(\times 10^{3} / \mathrm{ml}\right)$ & 0.138 & 0.710 & 0.997 & 0.983 & 1.012 & & & & & \\
\hline $\begin{array}{l}\text { Procalcitonin } \\
\text { (ng/ml) }\end{array}$ & 0.647 & 0.421 & 1.006 & 0.991 & 1.021 & & & & & \\
\hline CRP (mg/l) & 7.780 & 0.005 & 1.005 & 1.001 & 1.008 & 4.232 & 0.040 & 1.005 & 1.000 & 1.009 \\
\hline $\operatorname{HGB}(\mathrm{g} / \mathrm{dl})$ & 5.109 & 0.024 & 0.903 & 0.827 & 0.987 & & & & & \\
\hline HCT (\%) & 7.299 & 0.007 & 0.965 & 0.940 & 0.990 & 7.175 & 0.007 & 0.957 & 0.927 & 0.988 \\
\hline
\end{tabular}

$\mathrm{OR}=$ odds ratio. Multinominal Logistic Regression Nagelkerke $\mathrm{R}^{2}=0.512$ (Hosmer ve Lemeshow $p>0.05$ )

RDW $=$ Red blood cell distribution width, LOS H = Length of stay Hospital, LOS ICU = Length of stay Intensive Care Unit, MV = Mechanical Ventilation, APACHE II = Acute Physiology and Chronic Health Evaluation II, CCI = Charlson Comorbidite Index, SOFA $=$ Sequential Organ Failure Assessment, $\mathrm{WBC}=$ White blood cell, $\mathrm{CRP}=$ C-reactive protein, HGB $=$ Hemoglobin, HCT $=$ Hematocrit 
Table 3. The RDW cut-off value for mortality

\begin{tabular}{ccccccc}
\hline \multicolumn{2}{l}{ Test variables: RDW } & \multicolumn{1}{l}{ S } \\
\hline AUC & $\boldsymbol{p}$ value & \multicolumn{2}{c}{$\mathbf{9 5 \%}$ Confidence Interval } & Cut off & Sensitivity & Specifity \\
& & Lower & Upper & & & \\
0.580 & $\mathbf{0 . 0 0 2}$ & 0.539 & 0.658 & 16.5 & $70.9 \%$ & $47.7 \%$ \\
\hline
\end{tabular}

$\mathrm{AUC}=$ area under the curve

and $p$ value between 0.05 and 0.10 are excepted borderline significant level on all statistical analysis.

\section{RESULTS}

The comparison of the demographic, clinical and laboratory data of patients $(n=369)$ admitted to ICU with COPD, according to RDW groups are given in the Table 1. According to the results, 30-day mortality, LOS ICU, LOS H, MV duration, APACHE II, CCI, SOFA, WBC and procalcitonin values were found to be significantly higher and CRP levels were significantly lower in the group with high RDW values (Table 1).

Logistic regression analysis was done usin the possible factors that might affect mortality in cases with COPD. After the last step of the analysis $\left(6^{\text {th }}\right.$ step), six parameters (LOS H, MV duration, APACHE II, SOFA, CRP and HCT) were found to be the significant determinators for hospital mortality in cases with COPD, treated in ICU. The increase in MV duration, APACHE II scores, SOFA scores and CRP values and decrease in LOS H and HCT values are associated with increase hospital mortality in cases with COPD (Table 2).

A ROC curve analysis was applied to find the RDW cut off value in cases with COPD that determines the success of the RDW value in predicting mortality. It shows that RDW can differentiate in determining the mortality risk at COPD patients correctly at a rate of $58 \%$ (moderate). To answer the question of which value should be taken as the cut-off value for this test, the sensitivity value was $70.9 \%$ and the specificity value was $47.7 \%$, the cut off value was found to be 16.5. The risk of mortality was found statistically higher in patients with RDW of 16.5 and above (Table 3) (Fig. 1).
The age, RDW, inotrope use, MV duration, LOS H, APACHE II, CCI, SOFA, procalcitonin, CRP, HGB and HCT levels were found to be higher in patients with mortality compared to those without mortality (Table 4).

Spearman correlation analysis was applied to determine the relationship between RDW values and other variables of patients with COPD in intensive care and the results are given in the Table 5. Accordingly, there is a low level positive correlation between RDW and LOS H, LOS ICU, MV duration, APACHE II, CCI, SOFA, and WBC. There is a low level negative relationship between RDW and CRP, and HGB (Table 5).

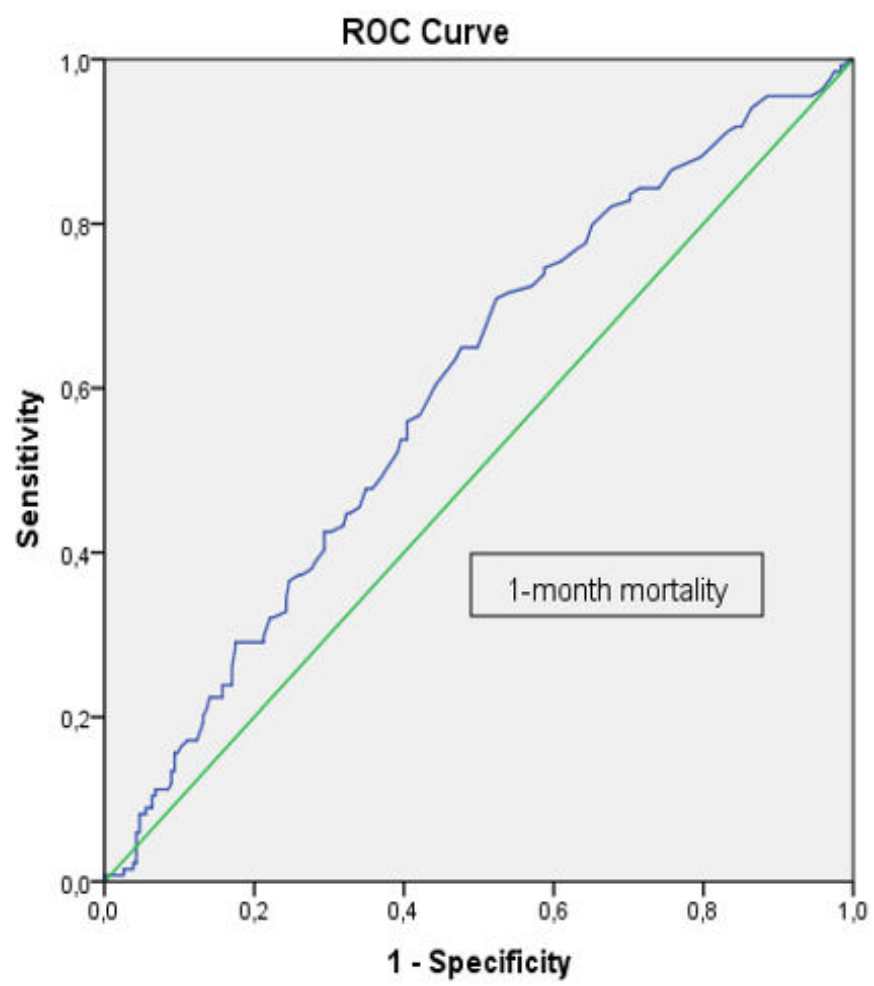

Fig. 1. ROC Curve Analysis for RDW value in predicting mortality. 
Table 4. Comparison between cases with and without mortality

\begin{tabular}{|c|c|c|c|}
\hline$n=369$ & $\begin{array}{c}\text { Mortality }(+) \\
\quad(n=134)\end{array}$ & $\begin{array}{c}\text { Mortality (-) } \\
\quad(n=235)\end{array}$ & $p$ value \\
\hline Sex, n (\%) & & & 0.580 \\
\hline Female & $48(35.8 \%)$ & $91(38.7 \%)$ & \\
\hline Male & $86(64.2 \%)$ & $144(61.3 \%)$ & \\
\hline Age (year) & $75(15)$ & $71(17)$ & 0.003 \\
\hline RDW & $17.2(4.32)$ & $16.2(3.9)$ & 0.002 \\
\hline Intrope use. $\mathrm{n}(\%)$ & $70(52.2 \%)$ & $18(7.7 \%)$ & $<0.001$ \\
\hline MV duration (day) & $3(6)$ & $0(0)$ & $<0.001$ \\
\hline LOS ICU (day) & $4.5(7)$ & $3(4)$ & 0.003 \\
\hline LOS H (day) & $17(19)$ & $16(15)$ & 0.235 \\
\hline APACHE II & $24(11)$ & $19(6)$ & $<0.001$ \\
\hline $\mathrm{CCI}$ & $7(3)$ & $6(3)$ & $<0.001$ \\
\hline SOFA & $7(4)$ & $4(2)$ & $<0.001$ \\
\hline WBC $\left(\times 10^{3} / \mathrm{ml}\right)$ & $12.05(6.85)$ & $11.5(6.7)$ & 0.616 \\
\hline Procalcitonin (ng/ml) & $0.31(2.2)$ & $0.15(0.71)$ & 0.002 \\
\hline $\mathrm{CRP}(\mathrm{mg} / \mathrm{l})$ & $17.4(54.55)$ & $8(25.79)$ & 0.002 \\
\hline $\operatorname{HGB}(\mathrm{g} / \mathrm{dl})$ & $12.2(3.8)$ & $11.65(3.4)$ & 0.039 \\
\hline $\mathrm{HCT}(\%)$ & $38.7(12.4)$ & $37.1(12)$ & 0.018 \\
\hline
\end{tabular}

Continuous variables are expressed as the median (IQR ) and categorical variables are expressed as either frequency or percentage. Continuous variables were compared with the mann whitney u test and categorical variables were compared using Pearson's chi-square test or fisher exact test. RDW = Red blood cell distribution width, LOS H = Length of stay Hospital, LOS ICU = Length of stay Intensive Care Unit, MV = Mechanical Ventilation, APACHE II = Acute Physiology and Chronic Health Evaluation II, CCI = Charlson Comorbidite Index, SOFA = Sequential Organ Failure Assessment, WBC $=$ White blood cell, $\mathrm{CRP}=\mathrm{C}$-reactive protein, HGB $=$ Hemoglobin, $\mathrm{HCT}=$ Hematocrit

\section{DISCUSSION}

In this study, we detected an association between RDW values and prognosis-mortality of patients with COPD in ICU. Our findings are as follows; firstly; 30day mortality, LOS H, LOS ICU and MV duration are higher in patients with high RDW values compared to those with normal RDW. Secondly; RDW is moderately succesfull in determining the mortality risk at COPD patients, with an accuracy of 58 percent. Thirdly; RDW is found to be one of the predictor for mortality. The other predictors of mortality was older age, inotrope use, MV duration, LOS H, APACHE II, CCI, SOFA, procalcitonin and CRP levels.

Similarly to our study, Osadnik et al. [13] also found an association between RDW and mortality. They thought that this association was due to the pos- sitive correlation between RDW and inflammation [13].

In a study of Lorente et al. [14]; septic patients who died had higher RDW values compared to survivors in the the first week of ICU admission. They also found association between RDW and SOFA, COPD, ischemic heart disease [14]. In our study, we used CCI for defining comorbidities and found COPD patients with higher RDW levels had also higher 30day mortality. Lorente et al. [14] showed that patients with RDW more than $15.5 \%$ had a $70 \%$ higher risk of death in the first 30 days than those with a lower RDW values.

Similar to our study, other researchers found that high RDW levels were a risk factor for mortality in patients with some certain medical conditions. RDW has been associated with increased mortality in inten- 
Table 5. The relation between RDW and other variables in COPD patients

\begin{tabular}{|c|c|c|}
\hline & & $\begin{array}{c}\text { RDW } \\
\mathrm{n}=369\end{array}$ \\
\hline \multirow[t]{2}{*}{ Age } & $\mathrm{r}$ & -0.041 \\
\hline & $p$ & 0.438 \\
\hline \multirow[t]{2}{*}{ LOS H } & $\mathrm{r}$ & 0.162 \\
\hline & $p$ & 0.002 \\
\hline \multirow[t]{2}{*}{ LOS ICU } & $\mathrm{r}$ & 0.144 \\
\hline & $p$ & 0.005 \\
\hline \multirow[t]{2}{*}{ MV Duration } & $\mathrm{r}$ & 0.170 \\
\hline & $p$ & 0.001 \\
\hline \multirow{3}{*}{ APACHE II } & $\mathrm{r}$ & 0.191 \\
\hline & $p$ & $<0.001$ \\
\hline & $\mathrm{n}$ & 368 \\
\hline \multirow[t]{2}{*}{$\mathrm{CCI}$} & $\mathrm{r}$ & 0.159 \\
\hline & $p$ & 0.002 \\
\hline \multirow[t]{2}{*}{ SOFA } & $\mathrm{r}$ & 0.133 \\
\hline & $p$ & 0.011 \\
\hline \multirow[t]{2}{*}{ WBC } & $\mathrm{r}$ & 0.114 \\
\hline & $p$ & 0.028 \\
\hline \multirow[t]{2}{*}{ Procalcitonin } & $\mathrm{r}$ & 0.082 \\
\hline & $p$ & 0.118 \\
\hline \multirow[t]{2}{*}{ CRP } & $\mathrm{r}$ & -0.116 \\
\hline & $p$ & 0.026 \\
\hline \multirow[t]{2}{*}{ HGB } & $\mathrm{r}$ & -0.154 \\
\hline & $p$ & 0.003 \\
\hline \multirow[t]{2}{*}{ HCT } & $\mathrm{r}$ & -0.060 \\
\hline & $p$ & 0.251 \\
\hline
\end{tabular}

RDW $=$ Red blood cell distribution width, $\mathrm{LOS} \mathrm{H}=$ Length of stay Hospital, LOS ICU $=$ Length of stay Intensive Care Unit, MV = Mechanical Ventilation, APACHE II = Acute Physiology and Chronic Health Evaluation II, $\mathrm{CCI}=$ Charlson Comorbidite Index, SOFA $=$ Sequential Organ Failure Assessment, $\mathrm{WBC}=$ White blood cell, $\mathrm{CRP}=\mathrm{C}$-reactive protein, $\mathrm{HGB}=$ Hemoglobin, $\mathrm{HCT}=$ Hematocrit

sive care patients $[8,9]$, patients with community acquired pneumonia [10], sepsis [15], gram-negative bacteremia [11]. Sadaka et al. [16] studied in patients with septic shock; they found that high RDW was associated with higher mortality. However, Budak et al. [17] did not find a relation between RDW and other inflammation markers like MPV, NRL and WBC count.

Zhang et al. [18] found that high RDW levels were associated with mortality on admission; however its predictive performance was suboptimal. Similarly, this study showed that RDW might determine the mortality risk at COPD patients with an accuracy of $58 \%$. There are some studies in the literature about relation with RDW and sepsis-mortality, but there is not enough study on COPD patients. Although RDW is shown as mortality indicator COPD patients in ICU, multicenter randomized studies with large number of the patients with other respiraory disease are required to confirm the role of RDW in prognosis of the pa- 
tients in ICU.

\section{Limitations}

Our study's limitations are as follows; a singlecenter study and has retrospective design, we measured RDW only in admission into the ICU therefore we can not comment on the RDW change by time and we have only included the patients with COPD and we might not generalize our findings to all patients with other respiratory diseases.

\section{CONCLUSION}

The risk of 30-day mortality, LOS H, LOS ICU and MV duration was higher in COPD patients with high RDW levels but there is a low level correlation.

\section{Authors' Contribution}

Study Conception: GED, MÖC; Study Design: GED, MÖC; Supervision: GED, MÖC; Funding: GED, MÖC; Materials: GED, MÖC; Data Collection and/or Processing: GED, MÖC; Statistical Analysis and/or Data Interpretation: GED, MÖC; Literature Review: GED, MÖC; Manuscript Preparation: GED and Critical Review: MÖC.

\section{Conflict of interest}

The authors disclosed no conflict of interest during the preparation or publication of this manuscript.

\section{Financing}

The authors disclosed that they did not receive any grant during conduction or writing of this study.

\section{REFERENCES}

1. Vajpayee N, Graham SS, Bem S. Basic examination of blood and bone marrow. In: McPherson RA, Pincus MR., eds., Henry's Clinical Diagnosis and Management by Laboratory Methods, Chapter 30, Elsevier Saunders: Philadelphia, 2011: pp.509-35. 2. Sangoi MB, Da Silva SH, da Silva JE, Moresco RN. Relation between red blood cell distribution width and mortality after acute myocardial infarction. Int J Cardiol 2011;146:278-80.

3. Forhecz Z, Gombos T, Borgulya G, Pozsonyi Z, Prohaszka Z, Jaetnoskuti L. Red cell distribution width in heart failure: predic- tion of clinical events and relationship with markers of ineffective erythropoiesis, inflammation, renal function, and nutritional state. Am Heart J 2009;158:659-66.

4. Hampole CV, Mehrotra AK, Thenappan T, Gomberg-Maitland M, Shah SJ. Usefulness of red cell distribution width as a prognostic marker in pulmonary hypertension. Am J Cardiol 2009;104:868-72.

5. Zorlu A, Bektasoglu G, Guven FM, Dogan OT, Gucuk E, Refiker $\mathrm{M}$, et al. Usefulness of admission red cell distribution width as a predictor of early mortality in patients with acute pulmonary embolism. Am J Cardiol 2012;109:128-34.

6. Ye Z, Smith C, Kullo IJ . Usefulness of red cell distribution width to predict mortality in patients with peripheral artery disease. Am J Cardiol 2011;107:1241-5.

7. Lou Y, Wang M, Mao W .Clinical usefulness of measuring red blood cell distribution width in patients with hepatitis B. PLoS One 2012;7:e37644.

8. Wang F, Pan W, Pan S, Ge J, Wang S, Chen M. Red cell distribution width as a novel predictor of mortality in ICU patients. Ann Med 2011;43:40-6.

9. Bazick HS, Chang D, Mahadevappa K, Gibbons FK, Christopher KB .Red cell distribution width and all-cause mortality in critically ill patients. Crit Care Med 2011;39:1913-21.

10. Lee JH, Chung HJ, Kim K, Jo YH, Rhee JE,Kim YJ, et al. Red cell distribution width as a prognostic marker in patients with community-acquired pneumonia.Am J Emerg Med 2013;31:729.

11. Ku NS, Kim HW, Oh HJ, Kim YC, Kim MH, Song JE, et al. Red blood cell distribution width is an independent predictor of mortality in patients with gram-negative bacteremia. Shock 2012;38:123-7.

12. Scharte M, Fink MP. Red blood cell physiology in critical illness. Crit Care Med 2003;31:S651-7.

13. Osadnik T, Strzelczyk J, Hawranek M, Lekston A, Wasilewski J, Kurek A, et al. Red cell distribution width is associated with long-term prognosis in patients with stable coronary artery disease. BMC Cardiovasc Disord 2013;13:113.

14. Lorente L, Martın MM, Gonzalez P, Violan JS, Ferreres J, Labarta L, et al. Red blood cell distribution width during the first week is associated with severity and mortality in septic patients. Plos One 2014;9:e105436.

15. Jo YH, Kim K, Lee JH, Kang C, Kim T, Park HM, et al. Red cell distribution width is a prognostic factor in severe sepsis and septic shock. Am J Emerg Med 2013;31:545-8.

16. Sadaka F, O'Brien J, Prakash S. Red cell distribution width and outcome in patients with septic shock. J Intensive Care Med 2013;28:307-13.

17. Budak YU, Huysal K, Gecgel SK, Ari H, Melek M, Yavuz S, et al. Red cell distribution width, other hematological parameters and atherogenic index of plasma in patients with clopidogrel and aspirin resistance. Eur Res J 2016;2:200-5.

18. Zhang Z, Xu X, Ni H, Deng H. Red cell distribution width is associated with hospital mortality in unselected critically ill patients. J Thorac Dis 2013;5:730-6. 